\title{
Electrical Resistivity Monitoring of the Thermomechanical Heater Test in Yucca Mountain
}

\author{
A. Ramirez \\ W. Daily \\ M. Buettner \\ D. LaBrecque
}

This paper was prepared for submittal to the

Symposium on the Application of Geophysics to

Engineering \& Environmental Problems

Reno, $N V$

March 23-26, 1997

December 1996

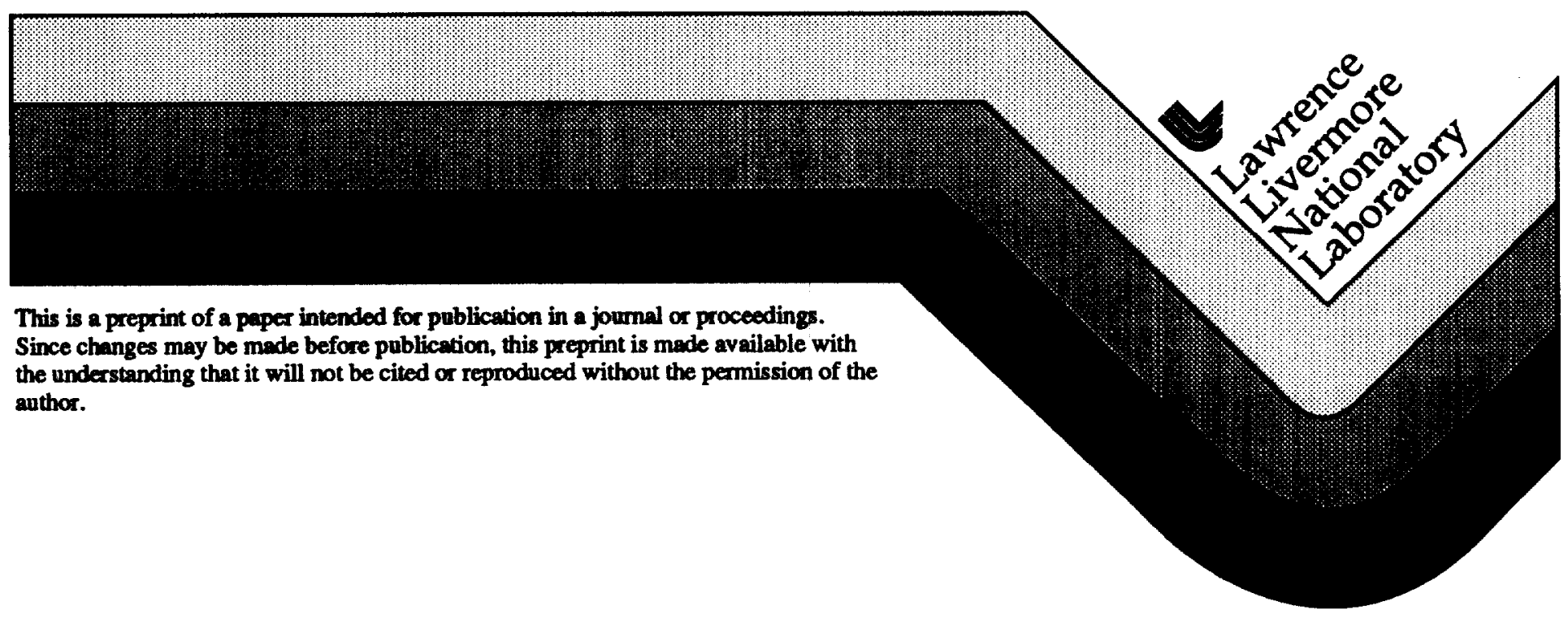




\section{DISCLAIMER}

This document was prepared as an account of work sponsored by an agency of the United States Government. Neither the United States Government nor the University of California nor any of their employees, makes any warranty, express or implied, or assumes any legal liability or responsibility for the accuracy, completeness, or usefulness of any information, apparatus, product, or process

disclosed, or represents that its use would not infringe privately owned rights. Reference herein to any specific commercial product, process, or service by trade name, trademark, manufacturer, or otherwise, does not necessarily constitute or imply its endorsement, recommendation, or favoring by the United States Government or the University of California. The views and opinions of authors expressed herein do not necessarily state or reflect those of the United States Government or the University of California, and shall not be used for advertising or product endorsement purposes. 


\title{
ELECTRICAL RESISTIVITY MONITORING OF THE THERMOMECHANICAL HEATER TEST IN YUCCA MOUNTAIN
}

\author{
A. Ramirez, W. Daily and M. Buettner \\ Lawrence Livermore National Laboratory \\ PO Box 808, L-206 \\ Livermore CA 94550 \\ D. LaBrecque \\ University of Arizona, Tucson, Arizona
}

\begin{abstract}
A test is being conducted in the densely welded Topopah Springs tuff within Yucca Mountain, Nevada to study the thermomechanical and hydrological behavior of this horizon when it is headed. A single $4 \mathrm{~kW}$ heater, placed in a horizontal borehole, was turned on August, 1996 and will continue to heat the rockmass until April 1997. Of the several thermal, mechanical and hydrological measurements being used to monitor the rockmass response, electrical resistance tomography (ERT) is being used to monitor the movement of liquid water with a special interest in the movement of condensate out of the system. Four boreholes, containing a total of 30 ERT electrodes, were drilled to form the sides of a 30 foot square with the heater at the center and perpendicular to the plane. Images of resistivity change were calculated using data collected before and during the heating episode. The changes recovered show a region of decreasing resistivity approximately centered around the heater. The size this region grows with time and the resistivity decreases become stronger. The changes in resistivity are caused by both temperature and saturation changes. The observed resistivity changes suggest that the rock adjacent to the heater dries as heating progresses. This dry region is surrounded by a region of increased saturation where steam recondenses and imbibes into the rock.
\end{abstract}

INTRODUCTION

Yucca Mountain Site Characterization Project (YMP) is studying the feasibility that Yucca Mountain can be used as a potential repository for highlevel nuclear wastes. The study includes prediction of the quantity and quality of water in the near-field of a repository. The quality and quantity of water in the near-field of a repository will affect the release rate of radioactive nuclides from waste packages, and the transport of the nuclides through the rock mass adjacent to the waste package. The radioactive decay heat from the high-level nuclear waste may generate coupled thermal-mechanical-hydrologicalchemical (TMHC) processes in the originally partially saturated Topopah Spring tuff, which is the potential host rock in Yucca Mountain. Modeling the coupled TMHC processes is necessary in order to predict the quantity and quality of water in the near-field environment of a repository. In situ thermal tests are required to increase the confidence level of the coupled TMHC models.

The Single Heater Test (SHT) is one of the in situ thermal tests being conducted in the Exploratory Studies Facility (ESF) in Yucca Mountain to 
enhance the understanding of the coupled processes. The primary objective of the SHT is to investigate the thermal-mechanical responses of the Topopah Spring tuff in Yucca Mountain.

This paper describes Electrical Resistance Tomography (ERT) surveys made during the SHT in order to map the changes in moisture content caused by temperature changes. The formation and movement of condensate within the fractured rock mass is of particular interest.

The SHT is located off the Observation Drift about $40 \mathrm{~m}$ from the Main Tunnel of the ESF, at about $2.8 \mathrm{~km}$ from the portal of the Tunnel. As shown in Figure 1, the heated block of the SHT is bounded by the Observation Drift, Thermal-mechanical Alcove, and Thermal-mechanical Alcove Extension. One single element electrical heater, about $5 \mathrm{~m}$ in length, was placed in a heater hole which was drilled horizontally into the heated block, near the middle of the Thermal-mechanical Alcove, about $1.5 \mathrm{~m}$ from the floor. The total power output of the heater is about $4 \mathrm{~kW}$; the heater was energized the morning of 8/26/96 and will remain energized until 4/97. Electrodes were positioned along four inclined boreholes drilled around the region of interest. A subset of the electrodes shown in Figure 1 were used to conduct ERT surveys around the heater.

Electrical resistance tomography (ERT) is a geophysical imaging technique which can be used to map subsurface resistivity. Rock mass heating creates temperature and liquid saturation changes which result in electrical resistivity changes that are readily measured. The ERT measurements consist of a series of voltage and current measurements from buried electrodes using an automated data collection system. The data is then processed to produce electrical resistivity tomographs using state of the art data inversion algorithms. These tomographs show the spatial distribution of the subsurface resistivities.

Here we describe briefly some of the important features of the 2D algorithm. For additional details, the reader is referred to Morelli and LaBrecque (1996). The algorithm solves both the forward and inverse problems. The forward problem is solved using a finite element technique in 2D. The inverse problem implements a regularized solution which minimizes an objective function. The objective of the inverse routine is to minimize the misfit between the forward modeling data and the field data, and a stabilizing functional of the parameters. The stabilizing functional is the solution's roughness. This means that the inverse procedure tries to find the smoothest resistivity model which fits the field data to a prescribed tolerance.

To calculate the changes in the rock's electrical resistivity, we compared a data set obtained after heating started, and a corresponding data set obtained prior to heating. One may consider performing the analysis by subtracting, pixel by pixel, two images corresponding to two different times. However, this approach could not be used because the resistivity structure was threedimensional, i.e., several boreholes containing metallic instruments, were located near the plane of interest. These metallic instruments caused large conductive anomalies and made the resistivity structure 3D. We chose to minimize the effects of these conductive anomalies by inverting the quantity: 


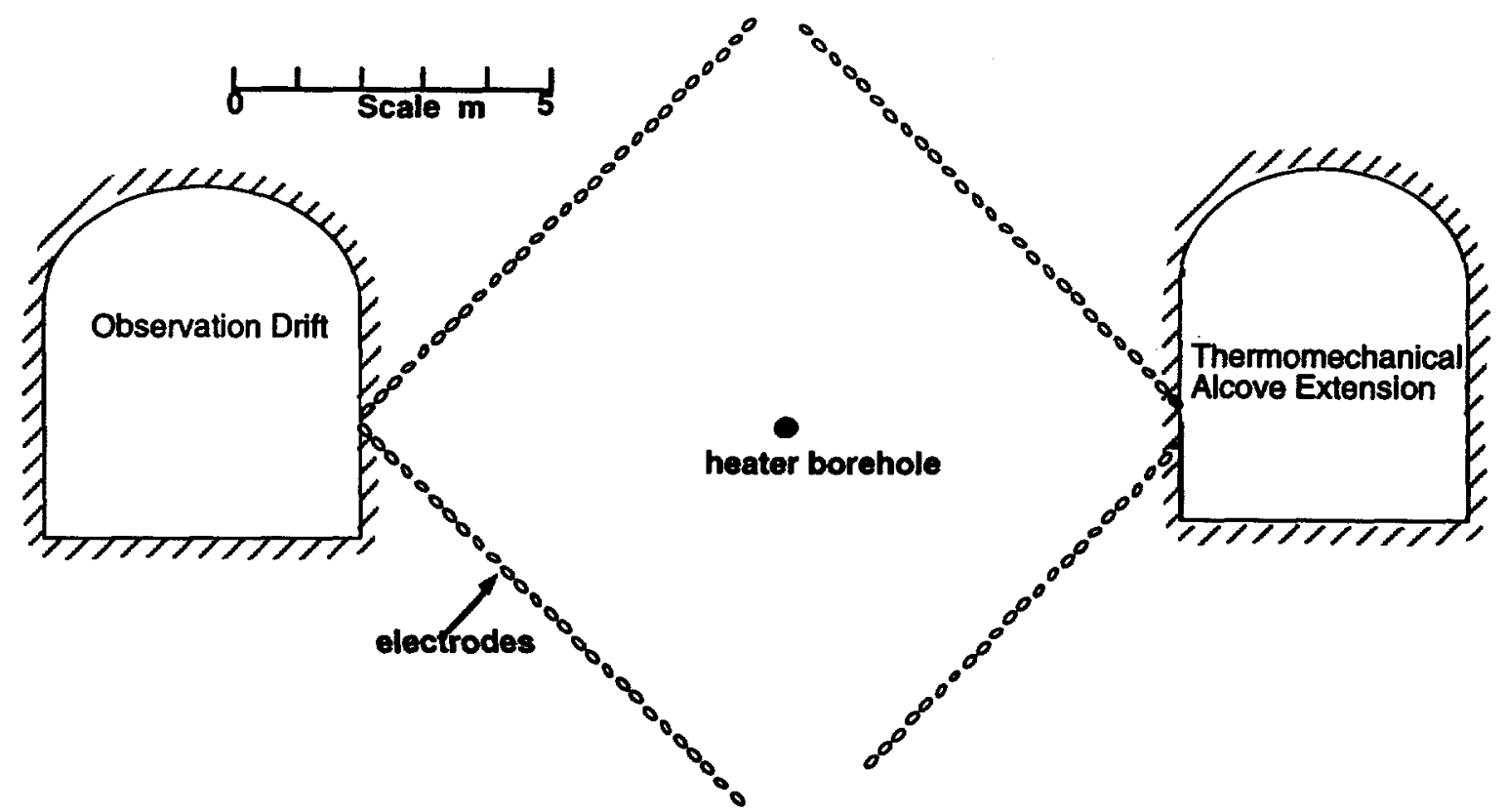

Figure 1 shows the location of the heater borehole relative to the electrode boreholes and underground openings.

$$
\frac{R_{a}}{R_{b}} \times R_{h}
$$

where $R_{a}$ is the measured transfer resistance after heating started, $R_{b}$ is the transfer resistance before heating and $R_{h}$ is the calculated transfer resistance for a model of uniform resistivity. This approach tends to reduce the effects of anomalies which remain constant in time.

\section{RESULTS AND DISCUSSION}

Figure 2 presents two-dimensional (2D) tomographs collected during the course of the SHT. The location of the heater is indicated on the figure. The images show the areas of the rock in which the electrical resistivity changed as a result of changes in temperature and saturation. Each image shows the changes detected for a given time relative to preheating conditions (data collected on 8/22/96). The image labeled "Repeatability Test (top left image) shows changes detected using two data sets collected two hours apart. No changes were expected at this time because heating had not yet begun (heating started on 8/26/96). Any changes observed in this image would be indicative of the effects of measurement error on the inversion process. On average, these "noise" images showed the resistivity ratio to deviate from 1.0 (i.e., perfect result when no changes occur) by $+/-0.05$. This analysis showed that changes of about $5 \%$ could be expected on the basis of measurement error. Therefore, the changes observed during heating need to be substantially bigger than $5 \%$ in order to be considered reliable. 


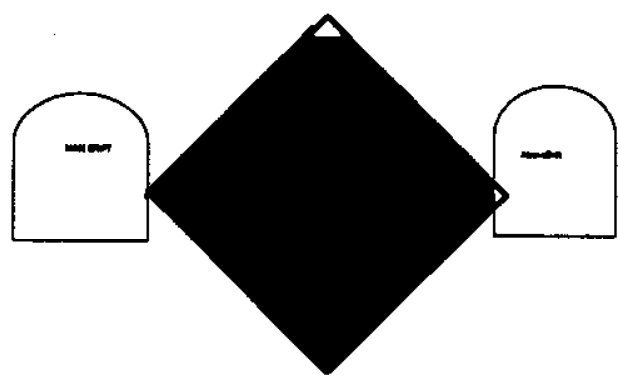

Repeatabilitv Test

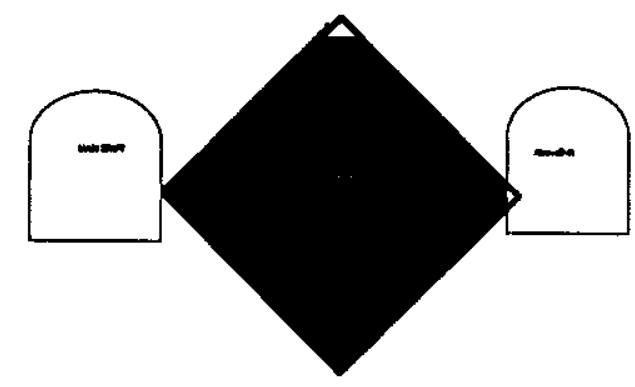

9/03/96
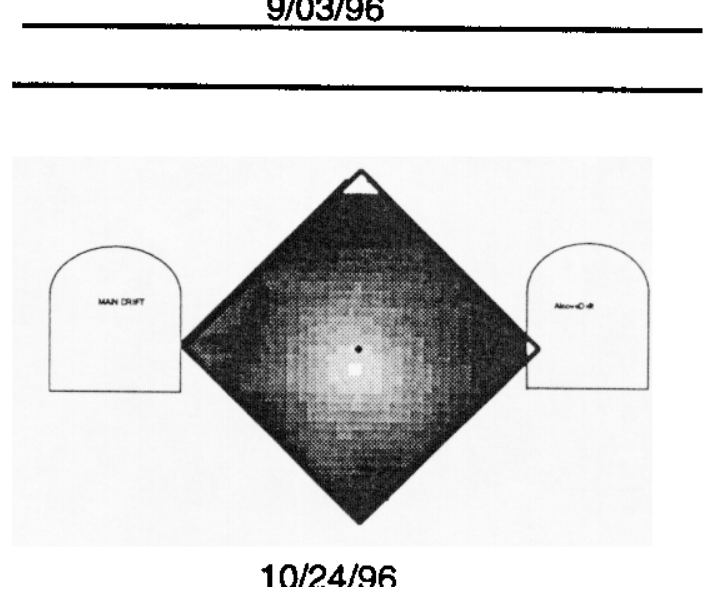

resistivity ratio

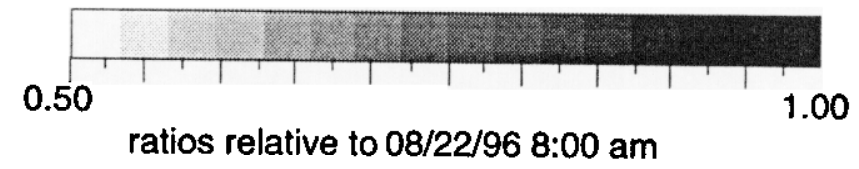

Figure 2 presents a series of two-dimensional ERT tomographs which show the decrease in electrical resistivity of the rockmass as heating progressed. Black tones indicate unchanged portions of the rockmass. Light colors (to the left of black on the gray scale) indicate portions of the image which show electrical resistivity decreases associated with heating. Heating started on $8 / 26 / 96$. 
The remaining images in Figure 2 show the resistivity changes after heating started. On $8 / 29$ (top right image), three days after heating started, the changes observed are of the same order as those expected to be caused by measurement error. The 9/03 image (center left image), show resistivity decreases relative to the pre-heating data as implied by ratio $<1.0$, which are considered reliable. The changes are roughly centered around the heater, as expected for a radially symmetric temperature field. The decreases grow stronger (i.e. ratio gets smaller) in 9/19 image as heating continued for another 16 days; also, the anomaly is approximately radially symmetric. The lower left image in Figure 2 shows the strongest resistivity decrease after almost two months of continuous heating. In this image, the resistivity decreases are no longer radially symmetric.

The resistivity changes in Figure 2 are influenced by changes in both saturation and temperature. In order to estimate the changes in saturation, we need to account for the changes that would be expected due to temperature change. The work of Waxman and Thomas (1954 a, $1954 \mathrm{~b}$ ) shows that surface conductance contributes a significant fraction of total conductance under some conditions and modifies the saturation - porosity - resistivity relationship. The conductance effects become more significant with increasing cation exchange capacity, decreasing $S_{w}$ (saturation), and increasing $R_{w}$ (water resistivity). The model proposed by Waxman and Thomas assumes: 1) a parallel conductance mechanism with free electrolyte and clay-exchange cation components, and 2) an exchange cation conductance, $B$ that depends on the equilibrating electrolyte concentration and temperature. At a fixed temperature, $\mathrm{B}$ approaches a maximum value for low $R_{w}$ and a minimum value for high $R_{w}$. The exchange cations provide a conductor for electrical current separate from, but parallel to, the conduction path through the pore space. We use this model to explain the observed decreases in bulk resistivity caused by heating and drying.

Chesnut and Cox (1978) derived the following formula from the work of Waxman and Thomas:

$$
R_{t}=\frac{\left(\phi S_{w}\right)^{-v} R_{w}}{1+R_{w} B Q_{v b}\left(\phi S_{w}\right)^{-1}}
$$

where:

$R_{W}=$ water resistivity, ohm-cm

$R_{t}=$ resistivity of water bearing sediment (or rock), ohm-cm

$\phi=$ fractional porosity

$S_{W}=$ water saturation as fraction of pore volume

$\mathrm{B}=$ equivalent conductance of exchangeable cations, $\left(\mathrm{cm}^{3} / \mathrm{meq}\right) /(\mathrm{ohm}-\mathrm{cm})$

$Q_{v b}=$ cation exchange capacity of sediment, meq per $\mathrm{cm}^{3}$ of bulk volume $v=$ combined saturation and porosity exponent, typically about 2 
For the case of the welded tuff at the experimental site, $R_{W}$ is fairly high (about $40 \mathrm{ohm}-\mathrm{m}$ ) and the cation exchange capacity is also fairly high (about $3.0 \mathrm{meq} / 100 \mathrm{~g}$ of rock); therefore, the second term in the denominator of equation (2) is large compared to unity. For large $R_{W}$, the exchange-ion conductance term, B, approaches $0.17 \mathrm{Bmax}$, which is a function of temperature only. Then, using equation 2, the ratio of resistivity at temperature $t_{1}$ and a water saturation of $S_{w_{1}}$ (before heating) to the resistivity at $t_{2}$ and a water saturation of $S_{\text {w2 }}$ (after heating) is:

$$
\frac{R_{t 1}}{R_{t 2}} \approx \frac{\left(S_{w 1}\right)^{-1}}{\left(S_{w 2}\right)^{-1}} \times \frac{B_{\max 2}}{B_{\max 1}}
$$

$R_{\mathrm{t} 1}$ is the resistivity before heating and $\mathrm{R}_{\mathrm{t} 2}$ is the resistivity after heating. $B_{\max 1}$ is the $B_{\max }$ corresponding to $t_{1}$ and $B_{\max 2}$ is the $B_{\max }$ corresponding to $t_{2}$. Note that equation (3) assumes that there are no changes in $R_{W}$; this may be an invalid assumption if rock/water chemical reactions occur with increasing temperate.

We can use equation 3 to make estimates of saturation change caused by heating if we assume some rock properties. We will assume that initial saturation $\left(S_{w_{1}}\right)$ of the rock unit was 0.92 ; this is the average saturation from core samples collected at the experimental site and reported by Wagner (1996). We also know that the initial temperature is $25^{\circ} \mathrm{C}$. $B_{\max }$ as function of temperature is obtained from Waxman and Thomas (1974). Figure 3 shows plots of saturation versus resistivity ratios $\left(R_{t 2}\right.$ - during heating resistivity / $R_{t 1}$ before heating resistivity) as a function of saturation $\left(S_{w_{2}}\right)$ and temperature. The figure shows, for example, that for a temperature of $100^{\circ} \mathrm{C}$, the resistivity ratio becomes one for a saturation of about 0.22 . This means that given a temperature of $100{ }^{\circ} \mathrm{C}$ the resistivity would decrease due to heating as long as the saturation $\left(\mathrm{S}_{\mathrm{w}_{2}}\right)$ was greater than $0.22(22 \%)$. We consider these saturation predictions as only rough estimates because of the number of assumptions that have to be made. We also know that the model used to generate the plots in Figure 3 underestimates the value of $R_{t 1} / R_{t 2}$ at saturations $<20 \%$ because the model does not account for the large resistivity increases that develop when the pore water occurs as isolated droplets instead of as continuous film.

The images in Figure 2 and the Figure 3 plots can be used together to interpret the resistivity changes in terms of saturation, if the temperatures are known. Temperature measurements have been made at various points in the rock around the heater. Some of these temperature measurements are shown in Figure 4 together with the tomograph corresponding to 10/25/96. Temperature readings collected along a horizontal radius are shown. Circles concentric with the heater borehole indicate the distance from the heater corresponding to the thermocouple location.

Using the observed resistivity ratios, we can estimate the change in liquid saturation throughout the rockmass. The resistivity ratio closest to the heater is about 0.55 . The closest temperature reading is about $0.6 \mathrm{~m}$ away and is about $100^{\circ} \mathrm{C}$. We know that temperatures rapidly increase closer to the heater; we will assume that the temperature is about $140^{\circ} \mathrm{C}$ close to the heater. 

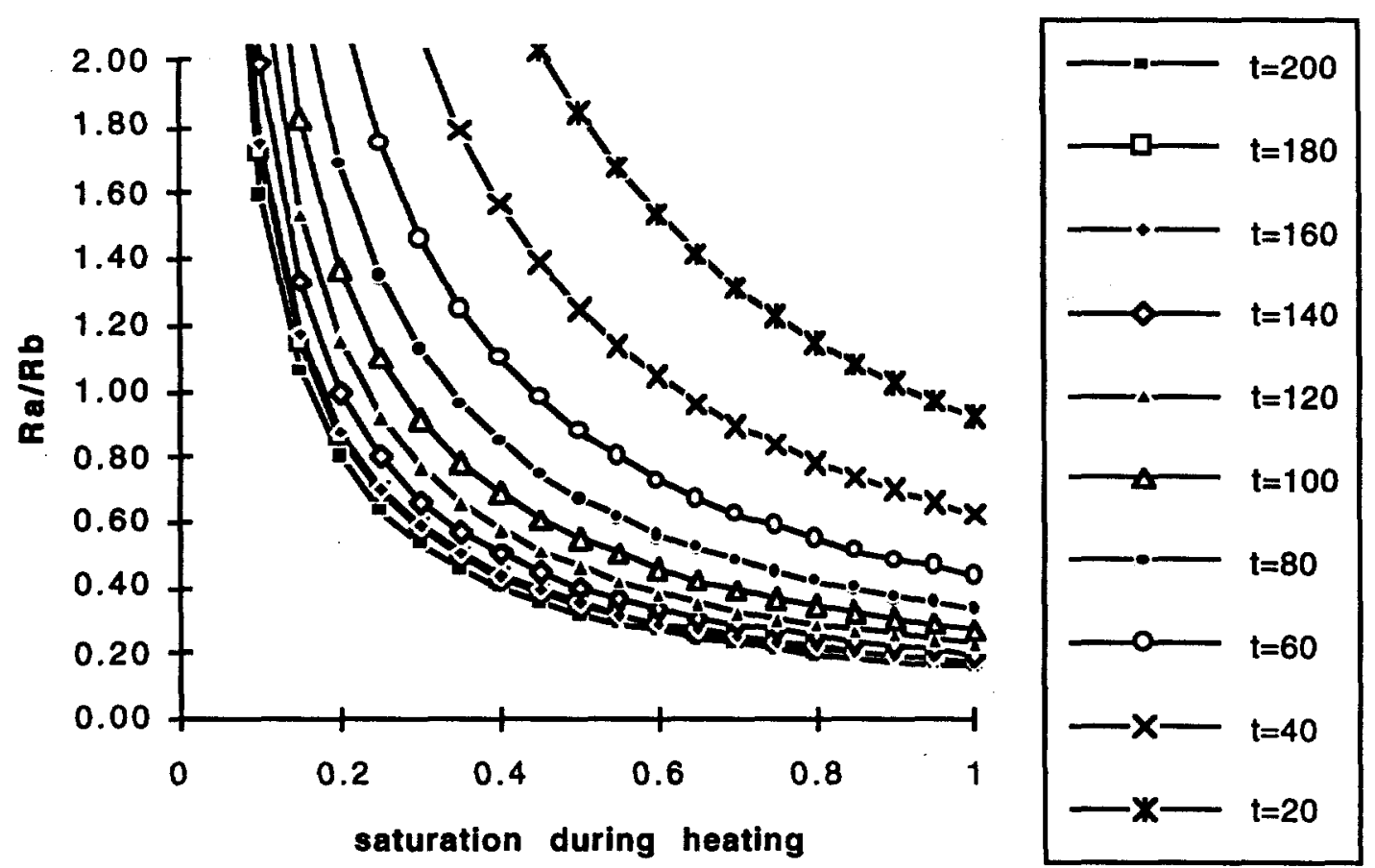

Figure 3 shows plots of saturation versus resistivity ratios (resistivity after heating $\left(R_{a}\right) /$ resistivity before heating $\left(R_{b}\right)$ ) as a function of saturation $\left(S_{w_{2}}\right)$ and temperature $\left(T_{2}\right)$. These plots assume that $S_{w 1}=0.92$ and $T_{2}=25^{\circ} \mathrm{C}$.

From Figure 3 we see that for a temperature of $140^{\circ} \mathrm{C}$ and an $\mathrm{Ra} / \mathrm{Rb}=0.6$, the saturation is about 0.35 . We can perform a similar analysis farther away from the heater. Consider the temperature of $43.7^{\circ} \mathrm{C}$ measured about $2.26 \mathrm{~m}$ away from the heater. The resistivity ratio that corresponds to this location is about 0.6. From Figure 3 we see that the saturation predicted for this case is close to 0.96 or $90 \%$. This analysis suggests that the region adjacent to the heater has suffered reductions in saturation while regions farther away show slight saturation increases. This interpretation is consistent with other work (previous field experiments and thermohydrologic modeling shown in Wilder (1996) that shows dry regions develop adjacent to the heater and that condensate accumulates in rock farther away. Similarly, the resistivity ratio above the heater at a distance of $2.26 \mathrm{~m}$ is about 0.6 while below the heater, the resistivity ratio is about 0.55 at the same distance. Assuming that the temperature at 2.26 $\mathrm{m}$ horizontal radial distance is the same as the temperature above and below the heater at the same distance, then the predicted saturation above the heater is about 0.95 and below it is about 1.0. These slight differences in saturation may be indicative of condensate drainage. The saturation interpretation suggested is considered plausible but not conclusive given the number of assumptions that had to be made.

The data collected on 10/25 indicate that the region of maximum change (lowest ratio) in Figure 4 is no longer centered around the heater. This region is now located below the heater. In our interpretation we will assume that the only two factors contributing to resistivity change are the temperature and saturation 
changes. Other studies have shown that heat transfer in this rock is conduction dominated. Since the thermal properties of the rock are reasonably homogeneous, to first order the temperature field is expected to be circular in shape and centered on the heater. If temperature increases were solely responsible for the changes in resistivity in Figure 4, then the resistivity changes would should a similar geometry. The images for 9/03 and 9/19 show anomalies that are roughly circular and approximately centered on the heater. The change in anomaly geometry between $9 / 19 / 96$ and 10/25/96 suggests that changes in saturation may be responsible. As water boils near the heater and recondenses in cooler regions, increases in saturation occur. Drainage of some of this condensate is expected along the predominantly vertical fractures present. The condensate can then be imbibed by the partially saturated rock surrounding the fracture. We suggest that the differences in behavior of the condensate above and below the heater are probably the cause of the asymmetry in Figure 4. Previous experimental and numerical modeling work shown in Wilder (1996) is consistent with this interpretation.

We consider the saturation estimate for rock adjacent to the heater an upper bound for the following reasons. 1) The inverse algorithm finds the smoothest model that fits the data. This implies that when there are sharp gradients in resistivity ratio values (as expected near the heater), the inverse problem will tend to find a more gradual gradient of values. In addition, the region of minimum resolution is located near the center of the image; this also would to tend to "smear" any gradients that exist. We believe that these two effects result in higher resistivity ratios (smaller change) around the heater than the true values. 2) Also, when a region of very dry rock develops around a heater, its likely surrounded by a region that is much wetter and very hot. The wet hot region is much more electrically conductive than the very hot and dry rock adjacent to the heater and completely surrounds it. This type of resistivity structure may not be detectable because the electrical energy tends to flow in the conductive annulus formed by the hot, wet rock and bypass the highly resistive core of hot dry rock adjacent to the heater.

\section{SUMMARY AND CONCLUSIONS}

To calculate the changes in the rock's electrical resistivity, we compared a data set obtained after heating started to a corresponding data set obtained prior to heating. The changes recovered show a region of decreasing resistivity approximately centered around the heater. The size of this region grows with time and the resistivity decreases become stronger. The changes in resistivity are caused by both temperature and saturation changes. The early tomographs show an anomaly centered on the heater and roughly radially symmetric; the largest resistivity changes occur closest to the heater. The last tomograph collected after 2 months of continuous heating showed that the anomaly is no longer centered on the heater; the largest resistivity changes appear somewhat below the heater. We interpret this change in position to mean that the condensate is preferentially draining downward. The observed resistivity changes suggest that the rock adjacent to the heater dries as heating progresses. This dry region is surrounded by a region of increased saturation where steam recondenses and imbibes into the rock. 


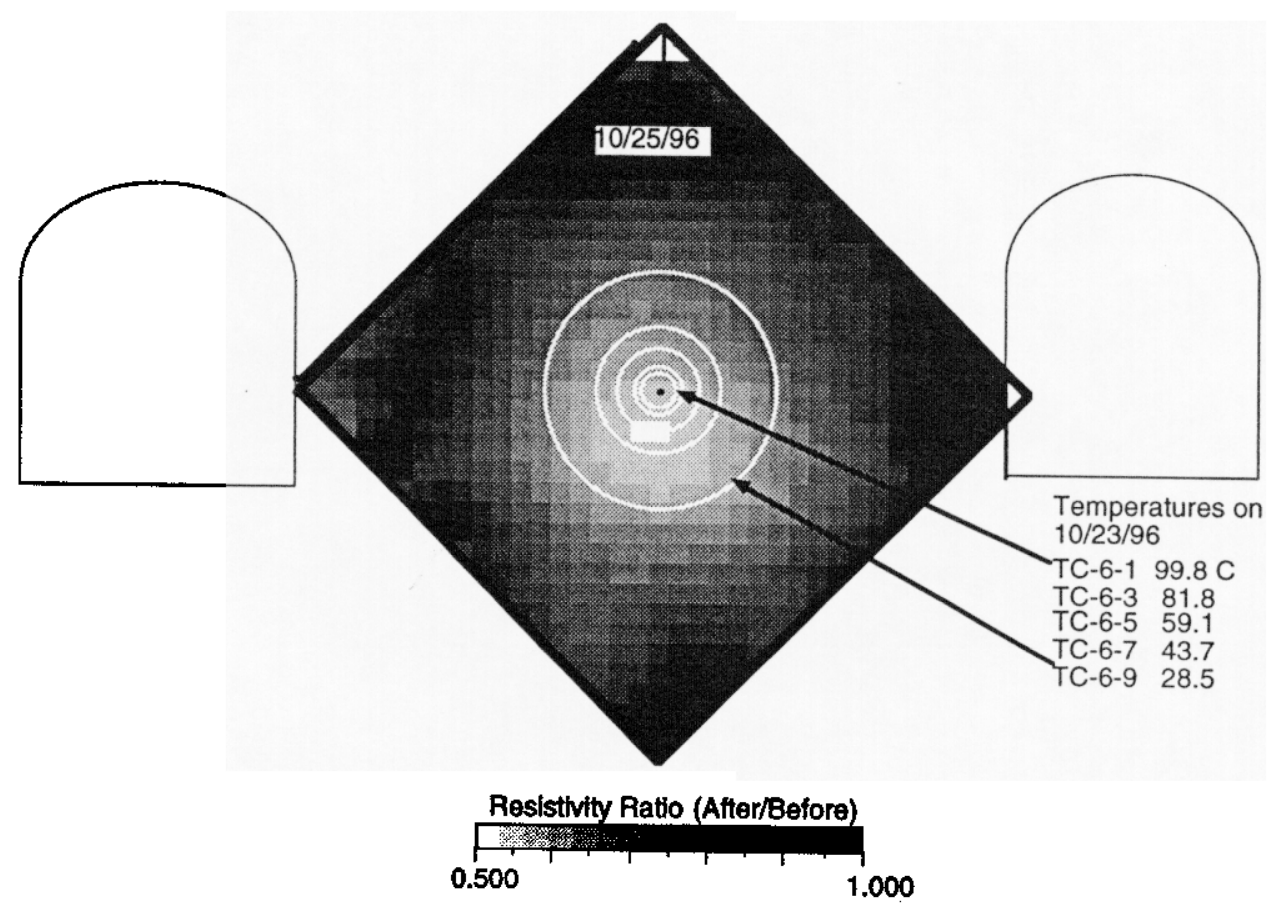

igure 4 shows the two-dimensional ERT tomograph corresponding $t$ $10 / 25 / 96$. Black tones indicate which portions of the images remain unchanged. Light colors to the left of black indicate which portions of the image show electrical resistivity decreases associated with heating. Also shown are temperatures at various radial distances to the heater.

\section{ACKNOWLEDGEMENTS:}

This work is performed under the auspices of the U.S. Department of Energy by Lawrence Livermore National Laboratory under contract W-7405-ENG-48. This work is supported by Yucca Mountain Site Characterization Project, LLNL.

\section{REFERENCES}

Chesnut, D.A. and D.O. Cox, (1978) "Log Analysis in a Rocky Mountain Heavy Oil Reservoir," SPWLA Nineteenth Annual Logging Symposium, June 13-16.

Morelli, G., 1996, and D. LaBrecque, 1996, Robust Scheme for ERT Inverse Modeling, Proceedings of the Symposium on the Application of Geophysics to Engineering and Environmental Problems, Keystone, CO, April 28-May 1, 1996; sponsored by the Environmental and Engineering Geophysical Society.

Wagner, R. A., 1996, Characterization of the ESF Thermal Test Area, TRW Inc, Yucca Mountain Site Characterization Project, Las Vegas NV, B000000000717-5705-00047 Rev 01. 
Waxman, M.H. and E.C. Thomas, 1974 a, "Electrical Conductivities in Shaly Sands - I. The Relation Between Hydrocarbon Saturation and Resistivity Index; The Relationship between Hydrocarbon Saturation and Resistivity Index," Journal of Petroleum Technology (Feb.) 213-218; Transactions AIME, 257.

Waxman, M.H. and E.C. Thomas, 1974 b, "Electrical Conductivities in Shaly Sands - II. The Relation Between Hydrocarbon Saturation and Resistivity Index; II. The Temperature Coefficient of Electrical Conductivity," Joumal of Petroleum Technology (Feb.) 218-225; Transactions AIME, 257.

Wilder, D. G., 1996, Near Field and Altered Zone Environment Report, Lawrence Livermore National Laboratory, UCRL-LR-124998, Livermore, CA. 


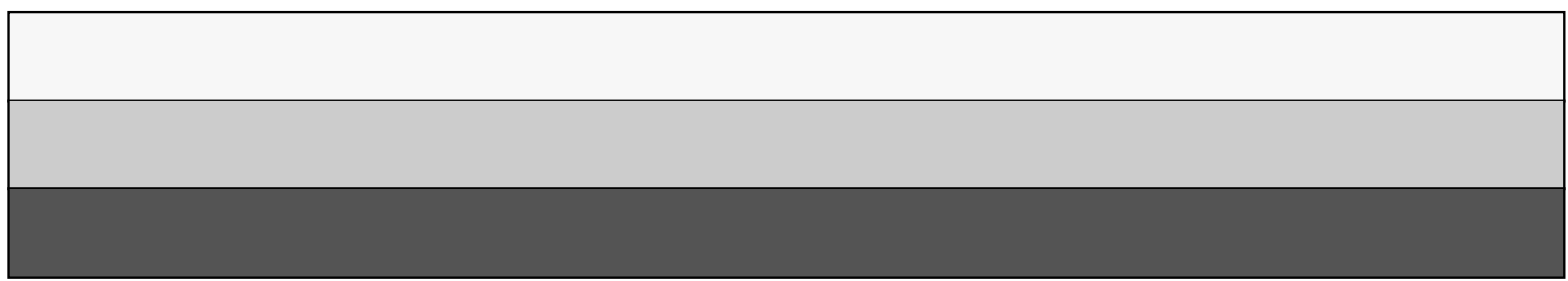

